\title{
Sorption-Photometric Determination of Iron(II) in Drinking Waters Using \\ Titanium Dioxide Based Sorbents Modified \\ with Polihexamethylene Guanidine, \\ Ferrozine or Ferene $\mathbf{S}$
}

\author{
Svetlana L. Didukh*, \\ Alexandra N. Muhina and Vladimir N. Losev \\ Siberian Federal University \\ 79 Svobodny, Krasnoyarsk, 660041 Russia
}

Received 28.11.2014, received in revised form 12.12.2014, accepted 20.01.2015

The titanium dioxide based sorbents were prepared by modifying polyhexamethylene guanidine, Ferrozine or Ferene S. Optimal conditions were found for concentration of iron(II). The sorbents quantitatively extract the iron(II) from solutions of pH 2.0-5.0 during $10 \mathrm{~min}$. Intensely colored iron(II) complexes are formed on the sorbents surface during sorption from solutions of pH 3.0-5.0 on $\mathrm{TiO}_{2}$-PHMG-Ferrozine and $\mathrm{pH}$ 2.5-5.0 on $\mathrm{TiO}_{2}$-PHMG-Ferene $\mathrm{S}$. The diffuse reflectance spectra have maxima at 560 and $600 \mathrm{~nm}$ for the sorbents with the functional groups of Ferrozine and Ferene $S$, respectively. This effect was suggested for development of procedures of sorption-photometric determination of iron(II). The calibration curves are linear in the range of $0.1-3.5 \mu \mathrm{g} / 0.1 \mathrm{~g} \mathrm{TiO} \mathrm{Z}^{-}$ PHMG-Ferrozine and 0.1-4.0 $\mu \mathrm{g} / 0.1 \mathrm{~g} \mathrm{TiO} \mathrm{O}_{2}-\mathrm{PHMG}$-Ferene $\mathrm{S}$. The detection limits of Fe (II) equal to $0.05 \mu \mathrm{g} / 0.1 \mathrm{~g}$ on the sorbent $\mathrm{TiO}_{2}-\mathrm{PHMG}$-Ferrozine and $0.04 \mu \mathrm{g} / 0.1 \mathrm{~g}$ on the sorbent $\mathrm{TiO}_{2}-\mathrm{PHMG}$ Ferene $S$. Technique is used for the determination of iron in drinking waters.

Keywords: sorption concentration, titanium dioxide, ferrozine, ferene s, iron (II), diffuse reflectance spectroscopy.

(C) Siberian Federal University. All rights reserved

* Corresponding author E-mail address: semdid@mail.ru 


\title{
Определение содержания железа(II) в питьевых водах сорбционно-фотометрическим методом \\ с использованием сорбентов на основе диоксида титана, последовательно модифицированного \\ полигексаметиленгуанидином, \\ Ferrozine и Ferene S
}

\author{
С.Л. Дидух, А.Н. Мухина, В.Н. Лосев \\ Сибирский федеральный университет \\ Россия, 660041, Красноярск, пр. Свободнылй, 79
}

Получень сорбенты на основе диоксида титана, последовательно модифиџированного полигексаметиленгуанидином, Ferrozine u Ferene S. Определены условия сорбционного концентрирования железа(II) модифицированными сорбентами. Количественное (98$99 \%$ извлечение железа(II) сорбентами достигается при рН 2,0-5,0. Время установления сорбционного равновесия не превышает 10 мин. При сорбции на поверхности сорбента образуются интенсивно окрашенные комплексы железа(II) с Ferrozine сиреневого $\left(\lambda_{\max }=560 \mathrm{HM}\right)$, a с Ferene $S$-синего $\left(\lambda_{\max }=600\right.$ нм) иввета. Максимальная интенсивность окраски развивается в течение 20 мин при рH 3,0-5,0 на ТіО -ПГМГ-Ferrozine и pH 2,5-5,0 на TiO-ПГМГ-Ferene S. Разработаны методики сорбиионно-фотометрического определения железа(II) с пределами обнаружения 0,05 мкг на 0,1 г ТіО-ПГМГ-Ferrozine и 0,04 мкг на 0,1 г TiO-ПГМГ-Ferene S. Линейность градуировочных графиков сохраняется до 3,5 и 4,0 мкг железа(II) на 0,1 г сорбентов для $\mathrm{TiO}_{2}$-ПГМГ-Ferrozine и $\mathrm{TiO}_{2}-П Г М Г$-Ferene $\mathrm{S}$ соответственно. Методика использована при определении железа в водопроводной и питьевых бутилированных водах.

Ключевые слова: модифицированный диоксид титана, Ferrozine, Ferene S, железо(II), сорбиия, сорбционно-фотометрическое определение.

Для концентрирования ионов металлов широко используют сорбенты на основе неорганических оксидов и диоксида титана, в частности [1]. Диоксид титана как матрица для синтеза сорбентов характеризуется доступностью, механической прочностью и химической стойкостью в кислых и щелочных средах, обладает достаточно высокой удельной поверхностью [2]. Диоксид титана применяли в качестве сорбента для извлечения мышьяка(III, V) из грунтовых вод [3], для концентрирования растворимых форм фосфора из природных вод [4], урана из пресной и морской воды [5] и их определения методом диффузионного градиента в тонких пленках $[4,5]$.

Для увеличения сорбционной способности диоксида титана по отношению к извлекаемым компонентам существуют различные способы активирования или модифицирования его поверхности. Известны способы активирования поверхности $\mathrm{TiO}_{2}$ путем его обработки постоянным электрическим полем [6] и ультразвуковой обработки [7] в кислых, щелочных сре- 
дах, в дистиллированной воде и растворе хлорида натрия. Для концентрирования ${ }^{99}$ Мо в виде молибдат-иона и ${ }^{99 \mathrm{~m}} \mathrm{Tc}$ в виде пертехнат-иона авторы работы [8] применяли гидратированный $\mathrm{TiO}_{2}$, сорбционная емкость которого по $\mathrm{MoO}_{4}{ }^{2-}$ в несколько раз выше сорбционной емкости негидратированного диоксида титана.

Сорбционные свойства модифицированного диоксида титана зависят от природы модификаторов. Диоксид титана с азотсодержащими функциональными группами изучали в качестве сорбента для азокрасителей [9]. Ферроцианидные сорбенты на основе гидратированного диоксида титана применяли для концентрирования цезия [10] и стронция [11].

Для получения сорбентов на основе диоксида титана для концентрирования и определения железа(II) в качестве модификаторов целесообразно использовать $\mathrm{N}$-гетероциклические органические основания: 2,2'-дипиридил, 1,10-фенантролин, пиридилтриазин и их производные, образующие с железом(II) интенсивно окрашенные комплексы [12-15].

3-(2-пиридил)-5,6-дифенил-1,2,4-триазин-4',4"-дисульфокислота (Ferrozine) и 3-(2пиридил)-5,6-ди(2-фурил)-1,2,4-триазин-5',5"-дисульфокислота (Ferene S) имеют в своем составе такую же функционально-аналитическую группу, как 1,10-фенантролин и 2,2'-дипиридил. По данным ЯМР [16], 3-(2-пиридил)-5,6-дифенил-1,2,4-триазин связывается с железом(II) бидентантно через атомы азота триазинового кольца и пиридил-радикала с образованием низкоспинового комплекса железа(II). Наличие сульфогрупп в составе реагентов делает их водорастворимыми и позволяет использовать для количественного определения железа(II) в водных растворах. Ferrozine и Ferene S образуют в водных растворах устойчивые трис-комплексы $\left[\mathrm{Fe}(\text { Ferrozine })_{3}\right]^{2+}(\lg \beta=17,46 \pm 0,37)$ и $\left[\mathrm{Fe}(\text { Ferene } \mathrm{S})_{3}\right]^{2+}(\lg \beta=16,45 \pm 0,25)$ [17].

Наличие на поверхности диоксида титана терминальных и мостиковых гидроксогрупп значительно затрудняет непосредственное закрепление на его поверхности реагентов Ferrozine и Ferene S из-за взаимного отталкивания сульфогрупп реагентов и депротонированных поверхностных гидроксильных групп. Для закрепления сульфопроизводного батофенатролина как одного из селективных реагентов на железо(II) нами [18] предложен способ предварительного модифицирования поверхности неорганических оксидов полигексаметиленгуанидином, имеющим в своем составе первичные и вторичные аминогруппы, способные к межмолекулярному взаимодействию как с сульфогруппами реагентов, так и с поверхностными гидроксильными группами.

Настоящая работа посвящена исследованию сорбционных и аналитических характеристик сорбентов на основе диоксида титана, модифицированного полигексаметиленгуанидином, Ferrozine и Ferene S по отношению к железу(II) и разработке методик его сорбционнофотометрического определения в водопроводной воде и питьевых бутилированных водах.

\section{Экспериментальная часть}

Peazeнты и pacmвopы. Дисперсный диоксид титана квалификации х.ч. (фракция 0,1-0,5 мкм, удельная поверхность 10 м²/). 5\%-ный раствор полигексаметиленгуанидина гидрохлорида (ПГМГ). 1·10-3 M растворы Ferrozine и Ferene S.

Исходный раствор железа(II) с концентрацией 100 мг/л готовили растворением точной навески $\mathrm{FeSO}_{4} \cdot 7 \mathrm{H}_{2} \mathrm{O}$ в $0,1 \mathrm{M}$ растворе $\mathrm{H}_{2} \mathrm{SO}_{4}$. Рабочие растворы готовили в день проведения эксперимента разбавлением исходного раствора деионизованной водой. Для предотвращения 
окисления железа(II) до железа(III) использовали 0,1 М раствор солянокислого гидроксиламина. Для создания необходимой кислотности растворов применяли растворы $\mathrm{HNO}_{3}, \mathrm{NaOH}$ квалификации ос.ч.

Annapamypa. Оптическую плотность растворов измеряли на спектрофотометре Cary 100 (Varian, Австралия). Иономер Seveneasy (Mettler-Toledo, Испания) использовали для измерения рН-растворов. Концентрацию железа в растворе определяли атомно-эмиссионным с индуктивно связанной плазмой методом на спектрометре Optima 5300 (Perkin-Elmer, США). Коэффициент диффузного отражения сорбентов регистрировали на спектрофотоколориметре «Пульсар» (НПО «Химавтоматика», Россия).

Для расчетов оптимальной геометрии молекул использовали полуэмпирический метод PM3, реализованный в программе GAMESS [19]. Площадь молекул рассчитывали для наиболее стабильных конформационных форм, исходя из полученных геометрических параметров и Ван-дер-Ваальсовых радиусов атомов.

Синтез сорбентов. Навеску диоксида титана массой 10 г выдерживали в растворе при $\mathrm{pH} 9$ в течение часа для активации поверхности. Затем со скоростью 1 мл/мин добавляли 100 мл 5\%-ного раствора ПГМГ, раствор сливали, сорбент промывали 100 мл 1,5 М раствора хлорида натрия и деионизованной водой до исчезновения качественной реакции на ПГМГ в промывном растворе по методике [20]. Полученный сорбент ( $\mathbf{T i O}_{2}-$ ПГМГ) высушивали при $60{ }^{\circ} \mathrm{C}$.

В градуированные пробирки с притертыми пробками вносили 0,1 г $\mathrm{TiO}_{2}$-ПГМГ, добавляли $1 \cdot 10^{-5}-1 \cdot 10^{-3} \mathrm{M}$ растворы Ferrozine или Ferene $\mathrm{S}, \mathrm{HNO}_{3}$ или $\mathrm{NaOH}$ для создания необходимого значения рН в диапазоне 2-9, перемешивали в течение 10 мин. Полученные сорбенты $\left(\mathbf{T i O}_{2}\right.$-ПГМГ-Ferrozine и $\mathbf{T i O}_{2}$-ПГМГ-Ferene $\left.\mathbf{S}\right)$ дважды промывали деионизованной водой. Степень извлечения реагентов определяли фотометрическим методом по анализу водной фазы по характеристическим полосам поглощения реагентов - 283 нм (Ferrozine) и 303 нм (Ferene S).

Сорбция железа(II) сорбентами $\mathrm{TiO}_{2}$-ПГМГ-Ferrozine и $\mathrm{TiO}_{2}$-ПГМГ-Ferene $\mathrm{S}$ в статическом режиме. В градуированные пробирки вводили от 0,1 до 5 мкг железа(II) в виде раствора в $0,1 \mathrm{M} \mathrm{H}_{2} \mathrm{SO}_{4}, 1$ мл 0,1 M раствора солянокислого гидроксиламина, $\mathrm{HNO}_{3}$ или $\mathrm{NaOH}$ для создания необходимого значения $\mathrm{pH}$ и деионизованную воду до 10 мл. Вносили 0,1 г сорбента $\mathrm{TiO}_{2}$-ПГМГ-Ferrozine или $\mathrm{TiO}_{2}$-ПГМГ-Ferene $\mathrm{S}$ и перемешивали в течение 1-20 мин. Сорбент отделяли от раствора декантацией, переносили во фторопластовую кювету, излишки воды убирали фильтровальной бумагой и регистрировали коэффициент диффузного отражения $(R)$ в диапазоне 380-720 нм. Спектры диффузного отражения (СДО) приведены в координатах: функция Гуревича-Кубелки-Мунка $\left(F(R)=(1-R)^{2} / 2 R\right)$ - длина волны, нм. Контроль за распределением железа осуществляли по анализу водной фазы атомно-эмиссионным с индуктивно связанной плазмой методом.

\section{Результаты и обсуждение}

Закрепление Ferrozine и Ferene $S$ на поверхности TiÖ-ПГМГ. Диоксид титана, модифицированный ПГМГ, извлекает Ferrozine и Ferene $\mathrm{S}$ из растворов в диапазоне $\mathrm{pH}$ 2,0-8,0, а максимальная степень извлечения реагента достигается при $\mathrm{pH} 3,5-7,0$. Снижение степени извлечения при $\mathrm{pH}<3,5$ связано с протонизацией сульфогрупп реагентов.

$$
-38-
$$


Сорбционная емкость $\mathrm{TiO}_{2}$-ПГМГ по реагентам, определенная из горизонтальных участков изотерм сорбции, составляет 15 мкМ/г для Ferrozine и 7,8 мкМ/г для Ferene S. При практически идентичной структуре молекул Ferrozine и Ferene S разница в сорбционных емкостях связана с пространственным расположением закрепленных реагентов относительно поверх-

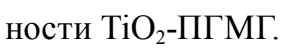

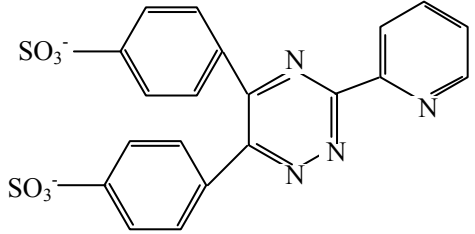

Ferrozine

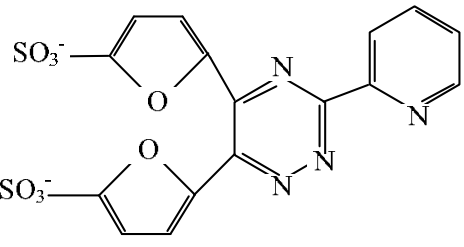

Ferene S

Согласно проведенным квантово-химическим расчетам молекула Ferrozine закрепляется за счет электростатического взаимодействия между сульфогруппами реагента и протонированными аминогруппами ПГМГ, закрепленного на поверхности $\mathrm{TiO}_{2}$, и располагается перпендикулярно поверхности сорбента. Молекула Ferene S закрепляется как за счет электростатического взаимодействия, так и за счет образования водородной связи между кислородом фурилового кольца и аминогруппами ПГМГ и располагается параллельно поверхности сорбента. При этих условиях площадь, занимаемая закрепленой молекулой

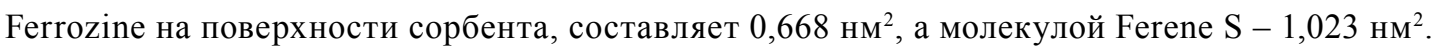
Исходя из сорбционной емкости сорбента $\mathrm{TiO}_{2}$-ПГМГ (n) по реагентам: 15 мкМ/Г для Ferrozine и 7,8 мкМ/г для Ferene S и площади молекул $\left(S_{m o l}\right)$, по уравнению $S=n \cdot N_{A} \cdot S_{m o l}$, где $N_{A}$ - число Авогадро, рассчитаны площади, занимаемые реагентами на поверхности сорбента при условии ее максимального заполнения реагентами, которые составили $6,0 \mathrm{M}^{2} / \Gamma$ для Ferrozine и 4,8 м²/Г для Ferene S. Полученные расчетные площади поверхности, занимаемые реагентами, меньше удельной поверхности $\mathrm{TiO}_{2}$; это может быть связано как с расположением активных центров - аминогрупп ПГМГ, так и с взаимным отталкиванием молекул реагентов.

Устойчивость закрепления органических реагентов на поверхности $\mathrm{TiO}_{2}$-ПГМГ изучали обработкой сорбентов $\mathrm{TiO}_{2}$-ПГМГ-Ferrozine и $\mathrm{TiO}_{2}$-ПГМГ-Ferene S 0,1-2 М растворами азотной кислоты. Ferene $\mathrm{S}$ и Ferrozine, закрепленные на поверхности $\mathrm{TiO}_{2}$-ПГМГ, устойчивы к воздействию слабокислых растворов, а их количественная десорбция достигается обработкой $2 \mathrm{M} \mathrm{HNO}_{3}$.

После сорбции Ferrozine сорбент $\mathrm{TiO}_{2}$-ПГМГ остается бесцветным, а после сорбции Ferene $\mathrm{S}$ окрашивается в светло-желтый цвет. СДО сорбентов $\mathrm{TiO}_{2}$-ПГМГ-Ferrozine и $\mathrm{TiO}_{2}$-ПГМГ-Ferene $\mathrm{S}$ представляют собой ниспадающие кривые без выраженных максимумов, расположенные на границе видимой и УФ-области.

Сорбционное концентрирование железа(II) сорбентами ТіО -ПГМГ-Fеrrozine и TiO (98-99 \%) извлекают железо(ІІ) из растворов в диапазоне рН 2,5-5,0 (рис. 1а, б, кривые 1) с временем установления сорбционного равновесия, не превышающем 10 мин. 
При сорбции железо(II) взаимодействует с атомами азота реагентов с образованием на поверхности $\mathrm{TiO}_{2}$-ПГМГ-Ferrozine комплексов сиреневого, а на поверхности $\mathrm{TiO}_{2}$-ПГМFerene S - синего цвета. В СДО поверхностных комплексов Fe(II) наблюдаются максимумы при 560 нм на $\mathrm{TiO}_{2}$-ПГМГ-Ferrozine и 600 нм на $\mathrm{TiO}_{2}$-ПГМГ-Ferene $\mathrm{S}$ (рис. 2). Время контакта фаз, необходимое для развития максимальной интенсивности окраски, составляет 20 мин. Максимальная интенсивность окраски поверхностного комплекса железа(II) с Ferrozine сохраняется в диапазоне $\mathrm{pH} 3,0-5,0$, c Ferene $\mathrm{S}$ - в диапазоне $\mathrm{pH}$ 2,5-5,0 (рис. 1a, б, кривые 2).

Поверхностные комплексы Fe(II)-Ferrozine и Fe(II)-Ferene S устойчивы к воздействию слабокислых сред. При обработке сорбентов $1 \mathrm{M} \mathrm{HNO}_{3}$ с поверхности сорбента десорбируется $10 \%$ железа, а $2 \mathrm{M} \mathrm{HNO}_{3}$ - не более $55 \%$.

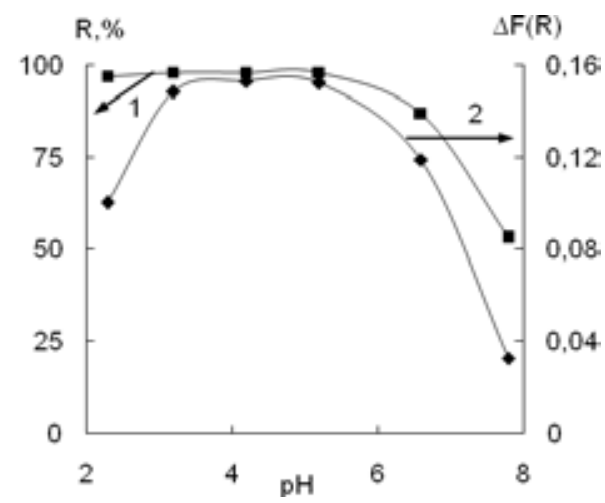

a

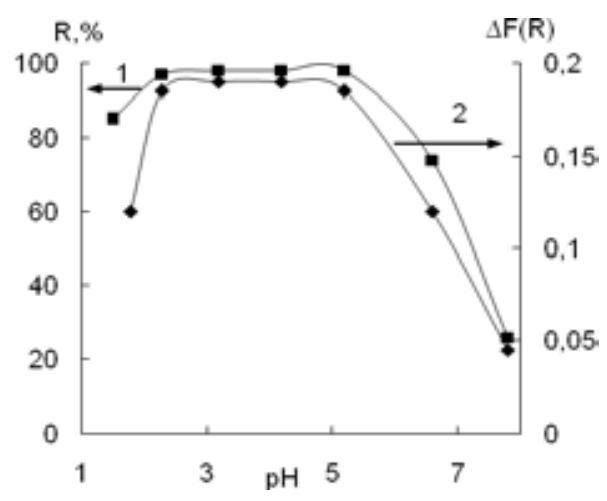

6

Рис. 1. Степень извлечения железа(II) (1) и зависимости $\Delta \mathrm{F}(\mathrm{R})(2)$ поверхностного комплекса железа(II) от $\mathrm{pH}$ на $\mathrm{TiO}_{2}$-ПГМГ-Ferrozine (a) и $\mathrm{TiO}_{2}$-ПГМГ-Ferene $\mathrm{S}$ (б) $\left(\mathrm{C}_{\mathrm{Fe}}=1\right.$ мкг $/ 0,1$ г сорбента; $\mathrm{V}=10$ мл; $0,01 \mathrm{M}$ $\left.\mathrm{NH}_{2} \mathrm{OH}\right)$

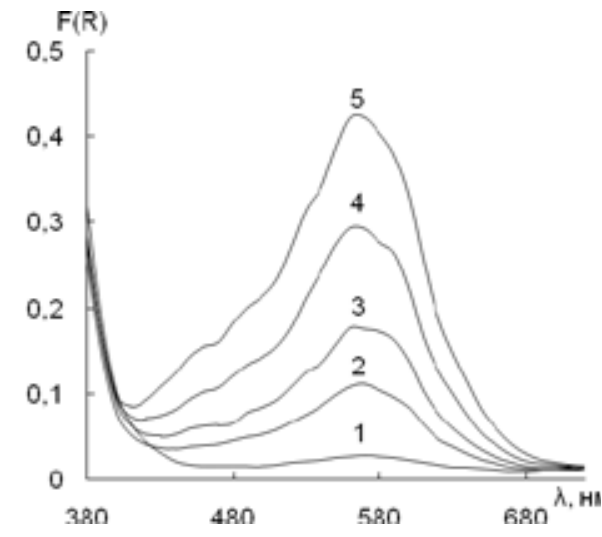

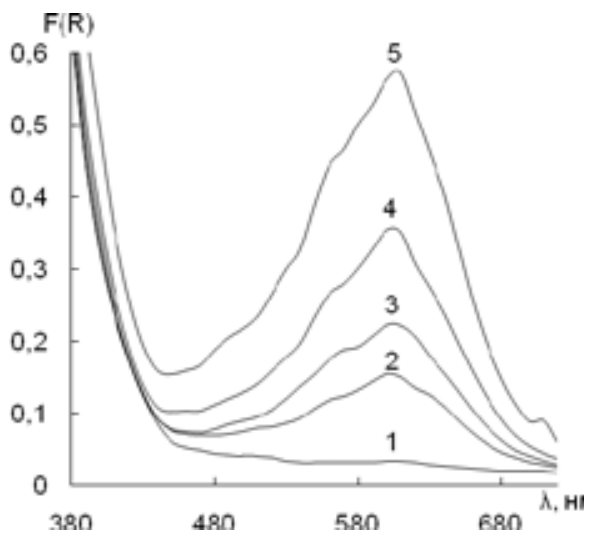

6

Рис. 2. Спектры диффузного отражения комплекса железа(II) на поверхности $\mathrm{TiO}_{2}$-ПГМГ-Ferrozine (a) и $\mathrm{TiO}_{2}$-ПГМГ-Ferene S (б) ( $\mathrm{C}_{\mathrm{Fe}}$ мкг/0,1 г сорбента: 0 (1), 0,6 (2), 1 (3), 2 (4), 3,5 (5); pH 3; 0,01 M NH 
Сорбционно-фотометрическое определение железа(II). Образование окрашенных комплексов железа(II) c Ferrozine и Ferene S, закрепленными на поверхности диоксида титана, использовано при разработке методик сорбционно-фотометрического определения железа(II) в водопроводной и питьевых бутилированных водах с применением спектроскопии диффузного отражения. С увеличением концентрации $\mathrm{Fe}(\mathrm{II})$ на поверхности $\mathrm{TiO}_{2}$-ПГМГ-Ferrozine и $\mathrm{TiO}_{2}$ ПГМГ-Ferene S пропорционально возрастает интенсивность окраски сорбентов (рис. 2).

Построение градуировочных графиков. В ряд градуированных пробирок вводят от 0,1 до 5 мкг железа(II) в виде раствора в $0,1 \mathrm{M} \mathrm{H}_{2} \mathrm{SO}_{4}, 1$ мл 0,1 М раствора солянокислого гидроксиламина, $\mathrm{NaOH}$ до $\mathrm{pH} 3$ и деионизованную воду до 10 мл. Вносят 0,1 г сорбента $\mathrm{TiO}_{2}$-ПГМГFerrozine или $\mathrm{TiO}_{2}$-ПГМГ-Ferene $\mathrm{S}$ и перемешивают 20 мин. Сорбент отделяют от раствора декантацией, переносят во фторопластовую кювету, излишки воды убирают фильтровальной бумагой и измеряют коэффициент диффузного отражения при 560 нм для $\mathrm{TiO}_{2}$-ПГМГ-Ferrozine и при 600 нм для $\mathrm{TiO}_{2}$-ПГМГ-Ferene $\mathrm{S}$. Полученные градуировочные зависимости описываются уравнениями:

$$
\begin{array}{ll}
\Delta \mathrm{F}(\mathrm{R})=(0,131 \pm 0,007) \cdot \mathrm{C} & \left(\mathrm{r}^{2}=0,994\right) \text { для } \mathrm{TiO}_{2} \text {-ПГМГ- Ferrozine; } \\
\Delta \mathrm{F}(\mathrm{R})=(0,152 \pm 0,008) \cdot \mathrm{C} & \left(\mathrm{r}^{2}=0,991\right) \text { для } \mathrm{TiO}_{2} \text {-ПГМГ- Ferene } \mathrm{S}
\end{array}
$$

где $\mathrm{C}$ - концентрация железа(II), мкг на 0,1 г сорбента; $\Delta \mathrm{F}(\mathrm{R})$ - разница между значением $\mathrm{F}(\mathrm{R})$ образца, содержащего железа(II) и $\mathrm{F}(\mathrm{R})$ холостого образца.

Метрологические характеристики разработанных сорбционно-фотометрических методик приведены в табл. 1.

Для изучения селективности сорбционно-фотометрического определения железа(II) создавались бинарные системы, содержащие 0,05 мкг/мл железа(II) и от 0,05 до 50 мкг/мл других ионов металлов и анионов. Определению 0,5 мкг $/ 0,1$ г сорбента железа(II) при рН 3 не мешают (в кратных количествах): $\mathrm{Na}(\mathrm{I}), \mathrm{K}(\mathrm{I}), \mathrm{Ca}(\mathrm{II}), \mathrm{Mg}(\mathrm{II}), \mathrm{Sr}(\mathrm{II}), \mathrm{Pb}(\mathrm{II}), \mathrm{Cd}(\mathrm{II}), \mathrm{Mn}(\mathrm{II})\left(10^{3}\right), \mathrm{Zn}(\mathrm{II})\left(10^{2}\right)$, $\mathrm{Al}(\mathrm{III})$ (10), $\mathrm{Ni}(\mathrm{II})$ (5); солевой фон по $\mathrm{NaCl}$ или $\mathrm{Na}_{2} \mathrm{SO}_{4}$ до 50 г/л. Наибольшее влияние на определение железа(II) оказывает $\mathrm{Cu}(\mathrm{I})$, образующая комплексы серого цвета c Ferrozine и Ferene $\mathrm{S}$. Мешающее влияние меди(I) маскировали раствором тиомочевины. В присутствии 2\%-ной тиомочевины определению железа(II) не мешают 10-кратные избытки меди(I).

Разработанные сорбционно-фотометрические методики использованы при определении общего содержания железа в виде железа(II) в водопроводной и питьевых бутилированных водах (табл. 2). Правильность результатов подтверждена атомно-эмиссионным методом с индуктивно связанной плазмой.

Таблица 1. Метрологические характеристики методик сорбционно-фотометрического определения

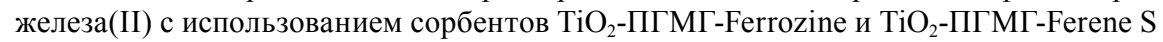

\begin{tabular}{|l|c|c|c|}
\hline \multicolumn{1}{|c|}{ Сорбент } & $\begin{array}{c}\text { Диапазон линейности } \\
\text { градуировочного графика, } \\
\text { мкг } \mathrm{Fe}(\mathrm{II}) / 0,1 \text { г }\end{array}$ & $\begin{array}{c}\text { Предел обнаружения, } \\
\text { мкг Fe(II)/0,1 г }\end{array}$ & $\mathrm{S}_{\mathrm{r}}$ \\
\hline $\mathrm{TiO}_{2}$-ПГМГ-Ferrozine & $0,1-3,5$ & 0,05 & 0,06 \\
\hline $\mathrm{TiO}_{2}$-ПГМГ-Ferene $\mathrm{S}$ & $0,1-4,0$ & 0,04 & 0,05 \\
\hline
\end{tabular}


Тест-методики определения железа(II). Образование интенсивно окрашенных комплексов железа(II) c Ferrozine и Ferene S на поверхности сорбентов использовано при разработке тест-методик визуального определения железа(II) в варианте цветовых шкал.

Методика тест - определения. В два ряда градуированных пробирок вводят от 0,1 до 4 мкг железа(II) в виде раствора в $0,1 \mathrm{M} \mathrm{H}_{2} \mathrm{SO}_{4}, 1$ мл 0,1 М раствора солянокислого гидроксиламина, $\mathrm{NaOH}$ до $\mathrm{pH} 3,0$, деионизованную воду до 10 мл. В первый ряд пробирок вносят 0,1 г $\mathrm{TiO}_{2}$ ПГМГ-Ferrozine, во второй - $\mathrm{TiO}_{2}$-ПГМГ-Ferene $\mathrm{S}$ и интенсивно перемешивают 20 мин. Растворы отделяют от сорбентов декантацией, сорбенты переносят в ячейки фторопластовой пластины последовательно с увеличением концентрации металла (цветовая шкала), излишки воды убирают фильтровальной бумагой. В ячейку отдельной пластины вносят сорбент с неизвестной концентрацией железа(II), которую перемещают вдоль цветовой шкалы, подбирая соответствие окраски сорбента.

На рис. 3 приведены фотографии цветовых шкал на основе сорбентов $\mathrm{TiO}_{2}$-ПГМГ-Ferrozine и $\mathrm{TiO}_{2}$-ПГМГ-Ferene $\mathrm{S}$. Как видно из рисунка, диапазон концентраций визуального определе-

Таблица 2. Результаты определения железа(II) в водопроводной и питьевых бутилированных водах $(\mathrm{n}=5$, $\mathrm{P}=0,95)$

\begin{tabular}{|c|c|c|c|}
\hline \multirow[b]{2}{*}{ Образец } & \multirow[b]{2}{*}{ Сорбент } & \multicolumn{2}{|c|}{ Найдено железа, мг/л } \\
\hline & & $\begin{array}{c}\text { сорбционно- } \\
\text { фотометрическим } \\
\text { методом }\end{array}$ & $\begin{array}{c}\text { атомно-эмиссионным } \\
\text { методом с ИСП }\end{array}$ \\
\hline \multirow[t]{2}{*}{ Водопроводная вода } & $\mathrm{TiO}_{2}-П Г М Г$-Ferrozine & $0,15 \pm 0,02$ & \multirow{2}{*}{$0,14 \pm 0,01$} \\
\hline & $\mathrm{TiO}_{2}-П Г М Г-$ Ferene $\mathrm{S}$ & $0,13 \pm 0,02$ & \\
\hline \multirow[t]{2}{*}{ Питьевая вода «Лель» } & $\mathrm{TiO}_{2}-П Г М Г$-Ferrozine & $0,059 \pm 0,005$ & \multirow{2}{*}{$0,060 \pm 0,002$} \\
\hline & $\mathrm{TiO}_{2}-П Г М Г$ - Ferene $\mathrm{S}$ & $0,062 \pm 0,004$ & \\
\hline \multirow{2}{*}{$\begin{array}{l}\text { Питьевая вода } \\
\text { «БонАква» }\end{array}$} & $\mathrm{TiO}_{2}-П Г М Г$-Ferrozine & $0,13 \pm 0,02$ & \multirow{2}{*}{$0,12 \pm 0,01$} \\
\hline & $\mathrm{TiO}_{2}-П Г М Г-$ Ferene $\mathrm{S}$ & $0,12 \pm 0,02$ & \\
\hline
\end{tabular}

$\mathrm{TiO}_{2}-П Г \mathrm{M}$-Ferrozine

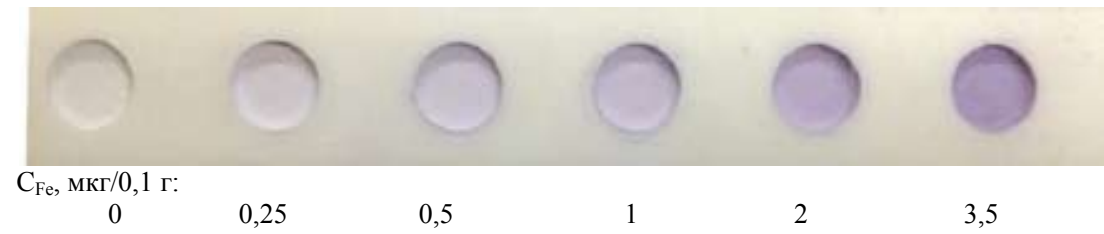

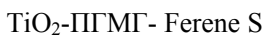

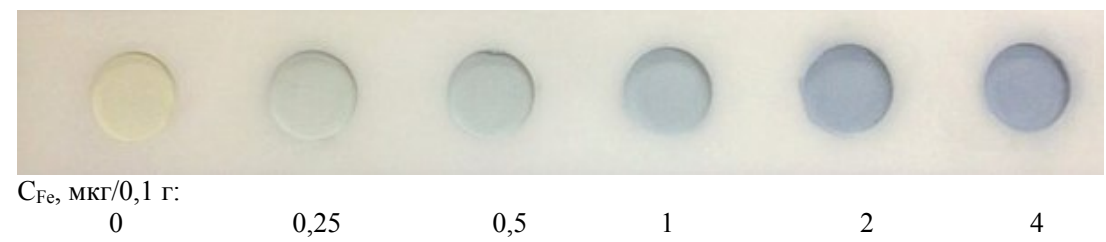

Рис. 3. Тест-шкалы для визуального определения $\mathrm{Fe}(\mathrm{II})$ с использованием $\mathrm{TiO}_{2}$-ПГМГ-Ferrozine и $\mathrm{TiO}_{2}$ ПГМГ- Ferene S 
ния железа(II) составляет 0,25-3,5 мкг $\mathrm{Fe}(\mathrm{II})$ на 0,1 г $\mathrm{TiO}_{2}$-ПГМГ-Ferrozine и 0,25-4,0 мкг Fe(II) на 0,1 г $\mathrm{TiO}_{2}$-ПГМГ-Ferene $\mathrm{S}$. При сорбции из 10 мл раствора диапазон визуально определяемых концентраций железа соответствует 0,025-0,35 мг/л и 0,025-0,4 мг/л соответственно для сорбентов с функциональными группами Ferrozine и Ferene S (ПДК железа в питьевой воде составляет $0,3 \mathrm{мг/л).}$

Полученные цветовые шкалы устойчивы, по крайней мере, в течение 6 месяцев.

Разработанные сорбционно-фотометрические и тест-методики характеризуются высокой правильностью и воспроизводимостью и позволяют определять содержание железа в природных и питьевых водах на уровне ПДК и ниже.

\section{Список литературы}

1. Золотов Ю.А. [и др.]. Сорбционное концентрирование микрокомпонентов из растворов. М.: Наука, 2007. 320 c. [Zolotov Ju.A. et. al. Sorption concentration of microcomponents solutions. M.: Science. 2007. 320 p. (in Russ.)]

2. Лисичкин Г.В. [и др.]. Химия привитых поверхностных соединений. М.: Физматлит, 2003. 592 c. [Lisichkin G.V. et. al. Chemistry grafted surface compounds. M.: Fizmatlit. 2003. 592 p. (in Russ.)]

3. Sunbaek Bang, Manish Patel, Lee Lippincott, Xiaoguang Meng. Removal of arsenic from groundwater by granular titanium dioxide adsorbent // Chemoshere. 2005. V.60. P. 389-397.

4. Jared J. Panther, Peter R. Teasdale, William W. Bennett. Comparing dissolved reactive phosphorus measured by DGT with ferrihydrite and titanium dioxide adsorbents: Anionic interferences, adsorbent capacity and deployment time // Analytica Chimica Acta. 2011. V. 698. P. 20-26.

5. Colin M. Hutchins, Jarden G. Panther, Fejyue Wang. Evaluation of a titanium dioxide-based DGT technique for measuring inorganic uranium species in fresh and marine waters // Talanta. 2012. V.97. P. $550-556$.

6. Смирнова В.В., Ильин А.П. Влияние постоянного электрического поля на сорбционные свойства диоксида титана // Фундаментальные исследования. Технические науки. 2013. № 6. C. 1366-1371. [Smirnova V.V., Il'in A.P. Influence of a constant electric field on the sorption properties of titanium dioxide // Fundamental research. Technical sciences. 2013. № 6. P. 1366-1371. (in Russ.)]

7. Смирнова В.В. Влияние структуры, свойств и оработки поверхности на сорбционную активность диоксида титана // Современные проблемы науки и образования. 2012. №5. С. 1-7. [Smirnova V.V. Influence of the structure, properties and processing with surface sorption activity of titanium dioxide // Modern problems of science and education. 2012. №5. P. 1-7. (in Russ.)]

8. Mushtaq A. [et al.]. Hydrated titanium dioxide as an adsorbent for ${ }^{99} \mathrm{Mo}^{9}{ }^{99 \mathrm{~m}} \mathrm{Tc}$ generator // Journal of Radiationalytical and Nuclear Chemistry. 1991. V.147. № 2. P. 257-261.

9. Magdalena Janus [et al.]. Study of Nitrogen-modified titanium dioxide as an Adsorbent for Azo Dyes // Adsorption Science \& Technology. 2009. V. 26. № 7. P. 501-513.

10. Ноговицына Е.В. Получение и свойства поверхностно-модифицированных сорбентов для извлечения цезия: автореф. дис. ... канд. хим. наук: 05.17.02. Екатеринбург, 2011. 19 с. [Nogovicyna E.V. Preparation and properties of surface-modified sorbents for extraction of cesium: autoabstract dis. cand. chem. sciences: 05.17.02. Ekaterinburg. 2011. 19 p. (in Russ.)] 
11. Воронина А.В., Семенищев В.С. Влияние поверхностного модифицирования гидратированного диоксида титана на селективность по отношению к стронцию // Радиохимия. 2013. № 1. C. 61-64. [Voronina A.V., Semenishhev V.S. Effect of surface modification of the hydrated titanium dioxide selectivity to strontium // Radiochemistry. 2013. № 1. P. 61-64. (in Russ.)]

12. Марченко 3., Бальцежак М. Методы спектрофотометрии в УФ и видимой областях в неорганическом анализе / пер. с польск. А.В. Гармаша. М.: БИНОМ, 2007. 711 с. [Marchenko Z., Bal'cezhak M. Methods of spectrophotometry in the UV and visible regions in inorganic analysis: translation from Polish A.V. Garmash. M.: BINOM, 2007. 711 p. (in Russ.)]

13. Алюкаева А.Ф., Иванов В.М., Цыцарин А.Г. Тестирование и цветометрическое определение железа(II,III) в форме сорбата фенентролината железа(II) // Журн. аналит. химии. 2002. T.57. №11. 1197-1201. [Aljukaeva A.F., Ivanov V.M., Cycarin A.G. // Testing and colorimetric determination of iron (II, III) in the form of sorbate fenentrolinata iron (II) // Journ. anal. chem. 2002. V.57. №11. P. 1197-1201. (in Russ.)]

14. Fresenius W., Schneider W. For the determination of iron(II) and total iron with 2,2' dipyridyl in mineral waters. Reduction of iron(III) with ascorbic acid // Joun. Analyt. Chem. 1976. 209. P. 340-341.

15. Peter L. C., Keith A. H. Determination of Fe(II) and total iron in natural waters with 3-(2pyridyl)-5,6-diphenyl-1,2,4-triazine (PDT) // Analytica Chimica Acta. 2000. V. 406. P. 289-302.

16. Hage R., Haasnoot J.G., Reedijk J. Structure and Properties of New Pyridyltriazine Low-Spin Iron(II) Complexes // Inorg. Chim. Acta. 1990. V 172. №1. P. 19-23.

17. Stauffer M. [et al.]. Limiting reactants in chemical analysis: influences of metals and ligands on calibration curves and formation constants for selected iron-ligand chelates // Stoichiometry and Research - The Impotance of Quantity in Biomedicine. 2012. P. 311-334.

18. Лосев В.Н., Дидух С.Л., Трофимчук А.К.. Сорбционно-фотометрическое определение железа с использованием сорбентов на основе неорганических оксидов с функциональными группами 4,7-дифенил-1,10-фенантролина // Известия вузов. Химия и хим. технология. 2009. T. 52. № 7. C. 32-36. [Losev V.N., Didukh S.L., Trofimchuk A.K. Sorption photometric determination of iron using sorbents on the basis of inorganic oxides having functional groups of 4,7-diphenyl-1,10phenanthroline // Izvestija VUZov. Himija i Him.tehnologija. 2009. V.52. №7. P. 32-36. (in Russ.)]

19. M.W.Schmidt, K.K.Baldridge, J.A.Boatz [et al.]. General Atomic and Molecular Electronic Structure System // J. Comput. Chem. 1993. 14. P. 1347-1363.

20. Ложкина О.В, Воробьева Е.И., Афиногенова А.Г. Инструкция по применению дезинфицирующего средства (кожного антисептика) «Триосепт-Аква». СПб.: ООО «НПО СпецСинтез», 2007. C.5-6. [Lozhkina O.V, Vorob'eva E.I., Afinogenova A.G. Instructions for use of the disinfectant (skin antiseptic) «Triosept-Aqua»/ SPb.: OOO «NPO SpecSintez». 2007. P.5-6. (in Russ.)] 